Advances in

Mobility Management for IP Networks

Editors:

Aisha Hassan Abdalla Hashim

Othman Khalifa

Shihab A. Hameed

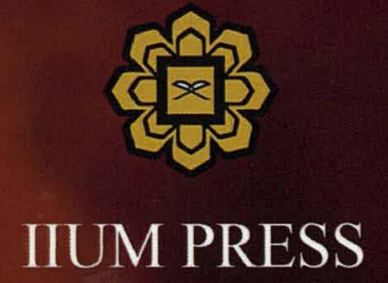


Advances in Mobility

Management for IP

Networks

Editors:

Aisha Hassan Abdalla Hashim

Othman Khalifa

Shihab A. Hameed

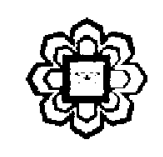

IIUM Press 
Published by:

IIUM Press

International lslamic University Malaysia

First fidition, 2011

CIIUM Press, IIUM

All rights reserved. No part of this publication may be reproduced, stored in a retrieval system, or transmitted, in any form or by any means, electronic, mechanical, photocopying, recording, or otherwise, without any prior written permission of the publisher.

Perpustakaan Negara Malaysia Cataloguing-in-Publication Data

Aisha Hassan Abdalla Hashim, Othman Khalifa, Shilah A. Hameed: Advances in Mobility Management for IP Networks

ISBN: $978-967-418-140-6$

Member of Majlis Penerbitan Ilmiah Malaysia- MAPIM

(Malaysian Scholarly Publishing Council)

Printed by :

IILM PRINTING SDN.BHD.

No. 1, Jalan Industri Batu Caves $1 / 3$

Taman Perindustrian Batu Caves

Batu Caves Centre Point

68100 Batu Caves

Selangor Darul Ehsan

Tel: +603-6188 1542 / 44 / 45 Fax +603-6188 1543

EMAIL: iiumprinting (d)yahoo.com 


\section{TABLE OF CONTENTS}

No. Title

Acknowledgement

Preface vi vi

Part 1: Internet Engineering Task Force (IETF) Approaches for 1 Multicast and Mobility Management

1 Introduction to Multicast Mobility Management

Aisha Hassan Abdalla Hashim, Shihab A. Hameed, Jamal Ibrahim

Daoud

2 Research Direction in Mobile IPv6

9

Azana Hafizah Mohd Aman, Aisha Hassan Abdalla Hashim, Sellami Ali, Wajdi Al-Khateeb

3 Operation of Context Transfer Protocol

Aisha Hassan Abdalla Hashin, Othman Khalifa, Azana Hafizah

Mohd Aman, Farhat Anwar, Shihab A. Hameed

4 The Study of Multicast Hierarchical Mobile IPv6

Azana Hafizah Mohd Aman, Aisha Hassan Abdalla Hashim, Akram

M. Zeki

5 The Siudy Of Multicast Listener Discovery

Aisha Hassan Abdalla Hashim, lmad Fakhri Taha Alshaikhli, Azana Hafizah Mohd Aman, Sellami Ali

6 MIPv6 Based Approaches for Mobility Management

Azana Hafizah Mohd Aman, Aisha Hassan Abdalla Hashim, Imad Fakhri Taha Alshaikhli

7 HMIPv6 Based Approaches for Mobility Management Aisha Hassan Abdalla Hashim, Wajdi Al-Khateeb, Farhat Anwar, Azana Halizah Mohd Aman 


\section{Part 2: Extensions to Mobile Multicast Schemes}

$8 \quad$ Introduction to Mobility Multicast Schemes

Aisha Hassan Abdalla Hashim, Azana Hafizah Mohd Aman, Sellami Ali, Othman Khalifa

9 Qualitative Study of Mobility Management Approaches

Azana Hafizah Mohd Aman, Aisha Hassan Abdalla Hashim, Imad Faklıri Taha Alshaikhli, Farhat Anwar

10 Architecture of $\mathrm{M}-\mathrm{HMIPv} 6 / \mathrm{CXTP}$

Aisha Hassan Abdalla Hashim, Azana Hafizah Mohd Aman

11 Intra Domain Movement of M-HMIPv6/ CXTP

Azana Hafizah Mohd Aman, Aisha Hassan Abdalla Hashim

12 Inter Domain Movement of M-HMIPv6/CXTP

Azana Hafizah Mohd Aman, Aisha Hassan Abdalla Hashim

13 Message Format ol M-HMIP46/CXTP

Aisha Hassan Abdalla Hashim, Azana Hafizah Mohd Aman

14 Signaling Flow of M-HMIPv6/ CXTP

Azana Hafizah Mohd Aman, Aisha Hassan Abdalla Hashim

15 Development of the Service Recovery Time and Signaling Cost Function

Aisha Hassan Abdalla Hashim, Azana Hafizah Mohd Aman

16 Evaluation Methods in Computer Networking

Aisha Hassan Abdalla Hashim, Azana Hafizah Mohd Aman

17 Ns2 Simulation Environment in M-HMIPv6

Omer Mahmoud, Azana Hafizah Mohd Aman

18 Service Recovery of Multicast Hierarchical Mobile IPv6 with

Context Transfer

Aisha Hassan Abdalla Hashim, Azana Hafizah Mohd Aman

19 The Study of Signaling Cost Of M-HMIPv6 with Context Transfer

Aisha Hassan Abdalla Hashim, Azana Hafizah Mohd Aman

20 Simulation Study of HMIPv6 And M-HMIPv6/CXTP

Azana Hafizah Mohd Aman, Aisha Hassan Abdalla Hashim 
21 Packet Loss in M-HMIPv6 with Context Transfer

Azana Hafizah Mohd Aman, Aisha Hassan Abdalla Hashim

22 Evaluation of Handover Latency in M-HMIPv6 with Context

Transfer

Azana Hafizah Mohd Aman, Aisha Hassan Abdalla Hashim

23 Future Directions

128

Azana Hafizah Mohd Aman, Omer Mahmoud, Aisha Hassan

Abdalla Hashim

24 MIPv6 Extensions

Abdulrhman Mohammed Bin Mahfodh, Abdi Nasir Ahmed, Aisha Hassan AbdalllaHashim, Omer Mahmoud, Md. Rafiqul Islam

25 IP Multicast

Abdulrhman Mohammed Bin Mahfodh, Abdi Nasir Ahmed, Aisha Hassan AbdalllaHashim, Md. Rafiqul Islam, Rashid Abdelhaleem Saced

26 Mobility Approaches to Support IP Multicast

Abdulrhman Mohammed Bin Mahfodh, Abdi Nasir Ahmed, Aisha Hassan AbdalllaHashim, Rashid Abdelhaleen Saeed, Omer Mahmoud

27 Hierarchichal Mobile Multicast Context Transfer (HMMCT) Abdulrhman Mohammed Bin Mahfodh, Abdi Nasir Ahmed, Aisha Hassan AbdalllaHashim, Omer Mahmood, Rashid Abdelhaleem Saeed

28 Simulation Evaluation of HMMCT

Abdulrhman Mohammed Bin Mahfodh, Abdi Nasir Ahmed, Aisha Hassan AbdalllaHashim, Omer Mahmood, Rashid Abdelhaleem Saeed

29 Analytical Study of HMMCT

Abdulrhman Mohammed Bin Mahfodh, Abdi Nasir Ahmed, Aisha Hassan Abdalla Hashim, Faiz Ahmed Mohamed Elfaki, Rashid Saad

\section{Part 3: QoS Approaches}

30 Introduction to QoS Approaches in Mobile Ad Hoc Networks

Mohammad Qabajeh, Aisha-Hassan A. Mashim, Othman Khalifa, Liana Qabajeh, Akram M. Zeki 
31 Routing Protocols For Ad Hoc Wireless Networks

Mohammad Qabajeh, Aisha-Hassan A. Hashim, Othman Khalifa,

Liana Qabajeh, Gharib Subhi Mahmoud Ahmed

32 Quality of Service (QoS) Issues In Manets

Mohammad Qabajeh, Aisha-Hassan A. Hashim, Othman Khalifa, Liana Qabajeh, Jamal Ibrahim Daoud

33 Supporting QoS Multicast Routing Over Mobile Ad Hoc Networks

Mohammad Qabajeh, Aisha-Hassan A. Hashim, Othman Khalifa, Liana Qabajeh

34 Position-Based Routing Protocols For Ad-Hoc Networks

Mohammad Qabajeh, Aisha-Hassan A. Hashim, Othman Khalifa, Liana Qabajeh

35 Simulation in Wireless Networks: An Overview

Mohammad Qabajeh, Aisha-Hassan A. Hashim, Othman Khalifa, Liana Qabajeh, Faiz Ahmed Mohamed Flfaki 


\title{
ROUTING PROTOCOLS FOR AD HOC WIRELESS NETWORKS
}

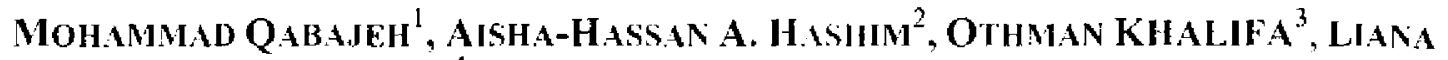 \\ QABAJEH ${ }^{4}$ GHARIB SIBHI MAHYOUD AHMED \\ ECE Dept, Fac: of Eng., International Islamic Unir. Malaysia (IVUM), Jalun Gombak, 53100 \\ Kuala Lumpur, Malavia.

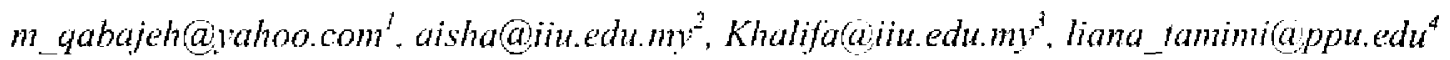

\subsection{INTRODUCTION}

Routing protocols are an activity or a function that is responsible for exchanging the route information, finding feasible paths between origin and destination and gathering information about the path break $[1,2]$. Routing protocols used in traditional wired networks cannot be directly applied in Ad hoc wireless networks. This is due to challenges characteristics of $\mathrm{Ad}$ hoc network including dynamic topology, lack of infrastructure, . Bandwidth constraint and shared wireless channel and Limited resources Therefore, routing in Ad hoc networks is a challenging task.

Routing protocols in general have two main different stages: they are routediscovery and data forwarding. In route discovery phase, route to a destination will be discovered by initiating route discovery request. Once the route has been established, data forwarding will be initiated and sent via the discovered routes. There are many routing protocols that have been proposed for Ad hoc networks. Some of the classilications of the routing protocols that are directly related to this research will be reviewed in the following subsections.

\subsection{Classifications of Routing Protocols in Ad-Hoc Networks}

Routing protocols for Ad-Hoc networks can be classified into several types based on different criteria. In this section we present the classification of routing protocols based on routing topology, information maintained at intermediate nodes, role assigned to the participating nodes and based on type of cast property.

\section{Classification based on routing topology}

Ad-Hoc wireless networks routing protocols in general can be classified based on the routing topology into two main categories: topologr-based and position-based [1].

Topolog?-based routing protocols use information about links that exist in the network to perform packet forwarding. They are, in turn. divided into three categories: proactive (table-driven or periodic) protocols, reactive (demand-driven or source-initiated) protocols, and hybrid (hierarchical or (reactive/proactive)) protocols[3].

In proactive routing protocols, the nodes are required to maintain the network topology information in the form of routing tables by exchanging the routing information periodically. In a proactive protocol, the information to determine the routes is immediately available so no additional time is needed to discover the hops in a route, thus 